\title{
Development of a Millet Destoner for Small Scale Farmers
}

\author{
${ }^{*}$ Aminu Saleh \\ Department of Agricultural and Bio-Resources Engineering, Ahmadu Bello University, Zaria, Nigeria \\ salehaminu@gmail.com
}

ORIGINAL RESEARCH ARTICLE

Received: 09-FEB-2021; Reviewed: 18-APR-2021; Accepted: 07-DEC-2021

http://dx.doi.org/10.46792/fuoyejet.v6i4.613

\begin{abstract}
Post-harvest processes of millet rely on labour-intensive manual operations in Nigeria while its produce is associated with contaminants. A manually-operated destoner was developed to increase grain value for commercial production and reduce drudgery. To construct the destoner sieves, physical properties of one thousand randomly selected grains were determined digital Vernier callipers. Millet grains to be destoned was fed through the upper portion of the destoner being operated through the crank handle while the pure grains were collected at the discharge outlet. Results obtained shows the geometric diameter of the grains increase progressively from $3.51-4.22 \mathrm{~mm}$ as moisture content increases. A screen aperture of $3.5 \mathrm{~mm}$ was constructed. Grains' surface area, volume and sphericity increased from $22.67-$ $34.82 \mathrm{~mm}^{2}, 8.19-13.98 \mathrm{~mm}^{3}$ and $0.691-0.776 \mathrm{~g}$ respectively. Mass, true density and terminal velocity of 1000 seed increased from $13.56-$ $43.84 \mathrm{~g}, 1548.91-1689.87 \mathrm{~kg} / \mathrm{m}^{3}$ and $2.69-4.58 \mathrm{~m} / \mathrm{s}$ respectively. The bulk density of millet also increased as moisture content increases but decreased beyond $12.5 \%$ moisture level indicating that millet floats on water and was transported with the aid of an auger. About $50 \mathrm{~kg}$ of millet was poured into the destoner to occupy its $1 / 3$ capacity while the remaining $2 / 3$ was filled with water. Destoner output was $3.00 t / h$ at $95 \%$ efficiency.
\end{abstract}

Keywords- Contaminants, Destoner, Millet, Processing, Properties

\section{INTRODUCTION}

Dearl millet (Pennisetum glaucum L.) is a tropical cereal crop indigenous to Africa. It is one of the oldest foods known to humans and possibly the first cereal grain to be used for domestic purposes. Millet is uniquely adapted to cultivation in harsh environmental growing conditions in sub-Saharan Africa. Millet constitutes a major source of energy and protein for millions of people in Africa and Asia. It is highly nutritious, non-glutinous and is not an acid forming food. It is also soothing and easy to digest. In addition, millet is tasty, with a mild sweet, nut-like flavour and contains a myriad of beneficial nutrients. It consists of about $15 \%$ protein and contains high amounts of fibre, B-complex vitamins. Millet serves as a major source of beverages (such as kunu and siro - in Hausa) in many countries including Nigeria. Worldwide, about 400 million people rely on millet for their subsistence. Millet is also used as feed for poultry, swine, fish and livestock, Kent, (1983) and Raily, (2006).

Traditionally, millet panicles are threshed by pounding the harvested heads in a mortar and pestle action in a hollowed-out log or on a cemented floor. The grain is separated from the chaff by winnowing. This method of threshing produces a mixture of broken and sound grains mixed with sand and pebbles thereby predisposes the millet to high vulnerability to poor quality of finished products due to contamination with dirt, stones and other impurities. In the developing world, (Sahelian Africa and Asian continent) post-harvest processing of millet is done manually, and mainly by women who are primarily responsible for the labour-intensive and time-consuming post-harvest processing operations.

${ }^{*}$ Corresponding Author

Section A- AGRICULTURAL ENGINEERING \& RELATED SCIENCES Can be cited as:

Saleh A. (2021): Development of a Millet Destoner for Small Scale Farmers, FUOYE Journal of Engineering and Technology (FUOYEJET), 6(4), 323-326. http://dx.doi.org/10.46792/fuoyejet.v6i4.613
Enormous utilization of the method coupled with the other associated challenges has, therefore necessitated the need for the development of a device (the destoner) capable of reducing the stress and removing the contaminants in order to improve the economics of millions of families relying on it for food and also for commercial processing.

\section{Materials ANd Methods}

Materials used for the construction of the destoner included a 200 litre iron drum; gauge 12 galvanized steel plate for the construction of the perforated sieve, auger and grain outlet; $25 \times 25$ angle iron for the frame; $10 \mathrm{~mm}$ $\varnothing$ mild steel rod for the construction of the main shaft and the crank handle; and a piece of wood that would be used to cover the handle. However, before undertaking the design work, many factors are taken into consideration. Millet is a unique cereal crop with a peculiar characteristic, particularly the tiny size of its grain (less than $4 \mathrm{~mm}$ ) and colour, as such it becomes imperative to carefully study these attributes before designing the thresher.

\subsection{Determination of Millet's Physical Properties}

To construct the destoner sieves, physical properties (shape, size, and moisture content) and the dimensions of one thousand randomly selected grains were determined. The number of seeds was presumed to be adequate as the sample mean representative of the entire population. Precision digital Vernier callipers with 0.01 decimal points were used for measuring grain dimensions. Since millet is relatively round in shape, its principal axis was considered as the thickness (diameter) as suggested by Mohsenin, (1986); Oje, (1993); Olaniyan, and Oje, (1999); and Firouzi et al. (2009). This was used to calculate the various aperture sizes of the destoner sieve as suggested by Mohsenin, (1986) and Galedar et al (2008). 


\subsection{Components and Construction of the Millet DESTONER}

A millet destoner was designed and constructed. Properties of millet determined were the guiding factors in the design. The following are the main components of the destoner is shown in Figure 1:

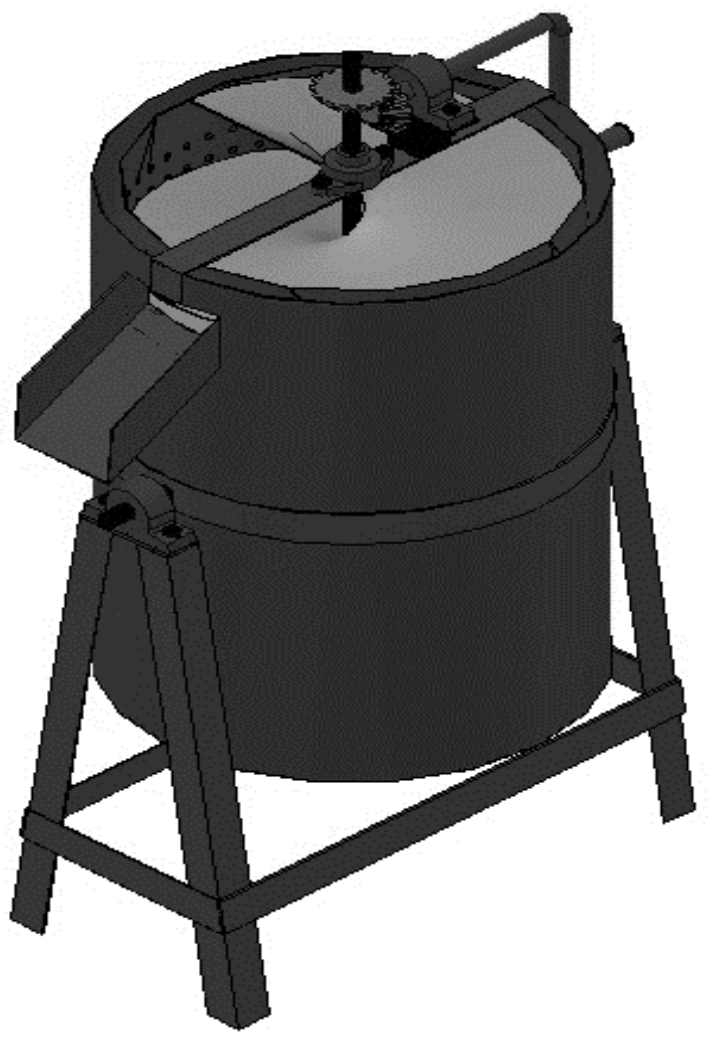

Fig. 1: Pictorial view of the Developed Millet Destoner

\subsubsection{Main Drum}

The drum serves as the main component of the destoner. It houses the entire destoning components. For ease of construction, it was made from 200 litres iron drum that could be accessed in almost every rural community where millet is processed. Its dimensions are $600 \mathrm{~mm}$ diameter and $800 \mathrm{~mm}$ height. The upper portion is completely cut off for ease of inserting the inner components. At the extreme top end is a discharge outlet that enable clean millet exit, while a discharge tap fixed at the lower part is meant draining excess water used during the destoning/ cleaning process.

\subsubsection{Perforated Drum}

Closely aligned with the main drum is a perforated drum. It is made of galvanised steel $540 \mathrm{~mm}$ diameter. It was welded with shaft and perforated with tiny round holes of about $3.5 \mathrm{~mm}$ diameter for the passage of stones and other contaminants through the discharge outlet by gravity. The actual separation of millet and contaminants takes place here since the millet grains to be separated are poured into this compartment. The perforated drum is coated with oil paint to avoid corrosion since water is used as the transport medium.

\subsubsection{Auger}

The auger is the spiral component that was welded to the main shaft of the destoner and it is made with $5 \mathrm{~mm}$ thickness galvanized steel. Its function is to transport millet from the bottom of the destoner to the discharge outlet. Its agitation also aids removal of other contaminants that might have been carried along with the millet.

\subsubsection{Crank Handle and Main Shaft}

The crank handle is the component through which rotary power is transmitted to the destoner through a set of driving gears to the main shaft. The shaft is made of mild steel rod of $10 \mathrm{~mm}$ diameter. It is $850 \mathrm{~mm}$ long. The handle is covered by a wood to provide comfort for the operator. The auger is welded to the main shaft, in order to provide the required motion needed for the separation. The assembly is supported by a flat bar mounted on top of the main drum.

\subsubsection{Frame}

A tilting support that serves as a frame was fixed at the bottom of the main drum such that the it could be turned to a convienient position to discharge the water and contaminants at an iterval of 10-15 mins when removal of the contaminats was expected to be completed. It is 700 $\mathrm{mm}$ high and $300 \mathrm{~mm}$ from the datum to accommodate a retainer for water drainage.

\subsubsection{Power Source}

The source of power for the design is basically human operated. Because of the low scale production of most millet farmers and the poor economic situation, cheap and availability of manual labour at the village level of rural Nigeria, manual source of power was choosen for this design. The normal output of human operator is about $0.075 \mathrm{~kW}$ which may be reduced to $0.022 \mathrm{~kW}$ when working continously (Eugene, 2007). Therefore, the power unit considered is capable of operating the destoner successfully for a maximum of 5 hrs per day. However, with increase in poduction capacity of the farmer, the destoner output could be manupulated by providing motorized source of power. This could be made possible by removing the manual handle and attaching a pulley on the shaft such that power could be trasmitted from the prime mover via a belt.

\subsection{Determination of Destoner OUtPut}

The performance of agricultural equipment is measured by the rate and quality at which operations were completed. Performance could also be measured by damage to produce due to machine's operation. Such performance was determined in terms of machine capacity. The machine capacity of the machine is the total mass of the material that passes through the grader at a particular time. The mass includes grains, chaff and straws that enter the grader. It is given by the formula:

$$
C_{t p}=W_{p}\left(\frac{k g}{\min }\right) \times \frac{1}{1000}\left(\frac{t}{k g}\right) \times 60\left(\frac{\min }{h}\right)
$$

where:

$$
\begin{gathered}
C_{t p}=\text { machine capacity of the grader, } \frac{\mathrm{kg}}{\mathrm{h}} \\
W_{p}=\text { mass of millet to be graded, } \mathrm{kg}
\end{gathered}
$$


Mechanical efficiency measures the effectiveness of the destoner in separating the foreign materials from the millet grains. It is measured as a ratio of the measured performance to the ideal performance of the destoner:

$$
\text { Efficiency }=\frac{\text { Measured Performance }}{\text { Ideal Performance }}
$$

\subsection{Principles of Operation of the Destoner}

The destoner (Figure 1) was designed to be operated by two people. While one person cranks and operates destoner via a handle, the second person feeds in the harvested millet grains through the upper portion of the destoner while the pure grains were collected at the discharge outlet. Grains fed into the perforated drum filled with water to about $2 / 3$ capacity moves by gravity towards the bottom of the rotating auger. As the kernels rotes inside the destoner, they also move upwards as the crank handle is being agitated. Heavier contaminants such as stones and metals sink down by gravitational force since the relative density of each of them was more than that of water being the transport medium.

Moreso, contaminants such as animal wastes would be washed off and/or dissolved in the water, thereby ensuring further cleaning of the grains. While agitation and upwards movement of the grains continues, small stones or particles of similar contaminants are forced out of the inner drum through the perforated openings, and were returned back to the base of the main drum. As the process continues, clean grains that reaches the top of the auger were collected through the grains outlet upon getting to the top of the auger. The outlet is fitted with a stopper that regulates and control grain discharge. When the operator is satisfied that cleaned grains are discharged from the system, and the run-off tap located below the main drum was opened in order to release the contaminants along with the dirty water.

\section{RESULTS AND Discussion}

\subsection{Physical Properties of Millet}

The physical properties of millet grains have been determined at $8 \%$ moisture content as suggested by Baryeh (2001). The results showed that geometric diameter of the grain increase progressively from 3.51 $4.22 \mathrm{~mm}$ with increase in moisture content; indicating that grain loss through the perforated openings of $3.5 \mathrm{~mm}$ diameter would be minimal when immersed in water as the destoner is in operation. Similarly, increment also occurred in the grains' surface area, volume and sphericity increased from 22.67 to $34.82 \mathrm{~mm}^{2}, 8.19$ to 13.98 $\mathrm{mm}^{3}$ and 0.691 to $0.776 \mathrm{~g}$ respectively. The 1000 seed mass, true density and terminal velocity also followed the trend with grain parameters earlier evaluated increased from $13.56-43.84 \mathrm{~g}, 1548.91-1689.87 \mathrm{~kg} / \mathrm{m}^{3}$ and 2.69 to 4.58 $\mathrm{m} / \mathrm{s}$ respectively. The bulk density of millet was noted to increase as the grain moisture content increased but decrease beyond $12.5 \%$ moisture level indicating that millet could float and be easily transported upwards by water as the transport medium with the aid of the auger.

\subsection{DESTONER OUTPUT}

A maximum of $50 \mathrm{~kg}$ of millet was found to be ideal for $2 / 3$ capacity of the filling the destoner when filled with water. Therefore, from equation (1), the destoner output was determined as follows:

$$
C_{t p}=50 \times \frac{t}{1000} \times \frac{60 \mathrm{~min}}{\mathrm{~h}}=3.00 \frac{\mathrm{t}}{\mathrm{h}}=3,000 \frac{\mathrm{kg}}{\mathrm{h}}
$$

\subsection{Mechanical Efficiency of the Destoner}

Several destoning trials were conducted to determine the efficiency of the destoner. Various ratios of clean millet and contaminants were fed into the destoner to be cleaned or destoned (Table 1). An average of $94.63 \%$ destoning efficiency was obtained (from equation 2). The results obtained would significantly add value to millet grain when compared with the traditional methods of removing contaminants through winnowing and aspiration. The efficiency of the destoner obtained was higher than the $90 \%$ obtained by Dawn et al. (2017) for millet destoning but lower than $98.89 \%$ separation efficiency recorded by Ojediran et al. (2018) for rice destoning.

\section{ConClusion}

The design, development and evaluation of a millet destoner was successfully carried out. The device was capable of washing, cleaning and separating grains from contaminant thereby increasing the quality of millet grains as well as reducing the drudgery involved in traditional methods of processing of the grain. The developed destoner was capable of destoning about 3,000 $\mathrm{kg}$ millet/hr with an average of $94.63 \%$ destoning efficiency. All materials used are locally sourced, while device is portable for ease of transportation from one field to another. Utilization of destoner in millet processing will impact on rural employment, trade and purchasing power of smallholder farming families, strengthen the economic capacity of women and improve household nutrition. Finally, this technology would also create more time for women to pursue other entrepreneurial activities, reduce cost of millet processing and drudgery associated with traditional method.

Table 1. Destoning Trials

\begin{tabular}{ccccccc}
\hline Trials & $\begin{array}{c}\text { Weight of } \\
\text { millet (Kg) }\end{array}$ & $\begin{array}{c}\text { Weight of } \\
\text { contaminant } \\
\text { (stones) } \mathbf{( K g )}\end{array}$ & $\begin{array}{c}\text { Average Weight of } \\
\text { Destoned Millet } \\
\mathbf{( k g )}\end{array}$ & $\begin{array}{c}\text { Weight of contaminants } \\
\text { retained in machine } \\
\mathbf{( K g )}\end{array}$ & $\begin{array}{c}\text { Destoning } \\
\text { Efficiency } \\
\mathbf{( \% )}\end{array}$ & $\begin{array}{c}\text { Destoning time } \\
\mathbf{( h )}\end{array}$ \\
\hline $\mathbf{1}$ & 40 & 10 & 38.00 & 12.00 & 95 \\
$\mathbf{2}$ & 45 & 5 & 42.80 & 7.29 & .067 \\
$\mathbf{3}$ & 48 & 2 & 45.50 & 4.50 & .066 \\
Average & 44 & 5.67 & 42.10 & 7.93 & .068 \\
\hline
\end{tabular}




\section{REFERENCES}

Baryeh E. A. (2001). Physical properties of Bambara groundnuts. Journal of Food Engineering, 47: 321-326.

Eugene A. A. (2007). Marks' Standard Handbook for Mechanical Engineers (11th Edition). Mc-Graw Hill, New York. Pg 9-4.

Dawn C. P. A., S. J. K. Annamalai1, Ravindra N., Anurag K. D. and S. Chakraborthy (2017). Performance studies on millet processing machinery for tribal livelihood Promotion. Journal of Applied and Natural Science 9 (3): 1796 -1800 (2017)

Firouzi, S.M., Vishgaei, N.S. and Kariami, B. (2009): Some Physical Properties of Groundnut (Aracishypogaea L.) as a Function of Moisture Content. American-Eurasian Journal Agriculture and Environmental Science, 6, 675-679.

Galedar, M.N., Jafari, A. and Tabatabaeefa, A. (2008) Some Physical Properties of Wild Pistachio Nut Andkernel as a Function of Moisture Content. Journal of Physics and Environmental and Agricultural Sciences, 22, 117-124.

Kent, N.L (1983): Technology of Cereals Pergamon Press, Oxford.
Mohsenin, N.N. (1986): Physical Properties of Plant and Animal Materials, Seconded. Gordon and Breach, Science Publishers Inc., New York, 58-76.

Oje, K. (1993): Some Engineering Properties of Thevetia Nut. Journal of Agricultural Engineering and Technology, 1, 38-45.

Ojediran, J. O., Okonkwo C. E., Okunola A. A., and Alake Adewumi Samuel (2018). Development of a motorized rice de-stoning machine. Agric. Eng. Int: CIGR Journal, Vol. 20, No. 4. Pp $202-$ 209.

Olaniyan, M.A. and Oje, K. (1999): Viscoelastic Behaviour of Shea Nuts under Application of Force. 21st Annual Conference of the Nigerian Institution of Agricultural Engineering (NIAE), Bauchi, Nigeria.

Raily, K. (2006) Whole Grain Millet, www.milletprocessing.com Accessed 12th January, 2021.

\section{APPENDIX}

Table A. Description of materials used for the construction of millet destoner

\begin{tabular}{lllll}
\hline S/N & Part Name & Material & Specifications $(\mathbf{m m})$ & Qty \\
\hline $\mathbf{1 .}$ & Main Drum & Oil Drum & 200 litres capacity & 1 \\
$\mathbf{2 .}$ & Perforated Drum & Mild Steel & $540 \times 600$ & 1 \\
3. & Frame & Angle Iron & $25 \times 25$ & $1 / 2$ length \\
4. & Crank Handle & Steel Rod & $\varnothing 10$ & 1 \\
$\mathbf{5 .}$ & Main Shaft & Steel Rod & $\varnothing 15$ & 1 \\
$\mathbf{6 .}$ & Auger & Mild Steel & $50 \times 600$ & 1 \\
7. & Grain Outlet & Mild Steel & $100 \times 200$ & 1 \\
\hline
\end{tabular}

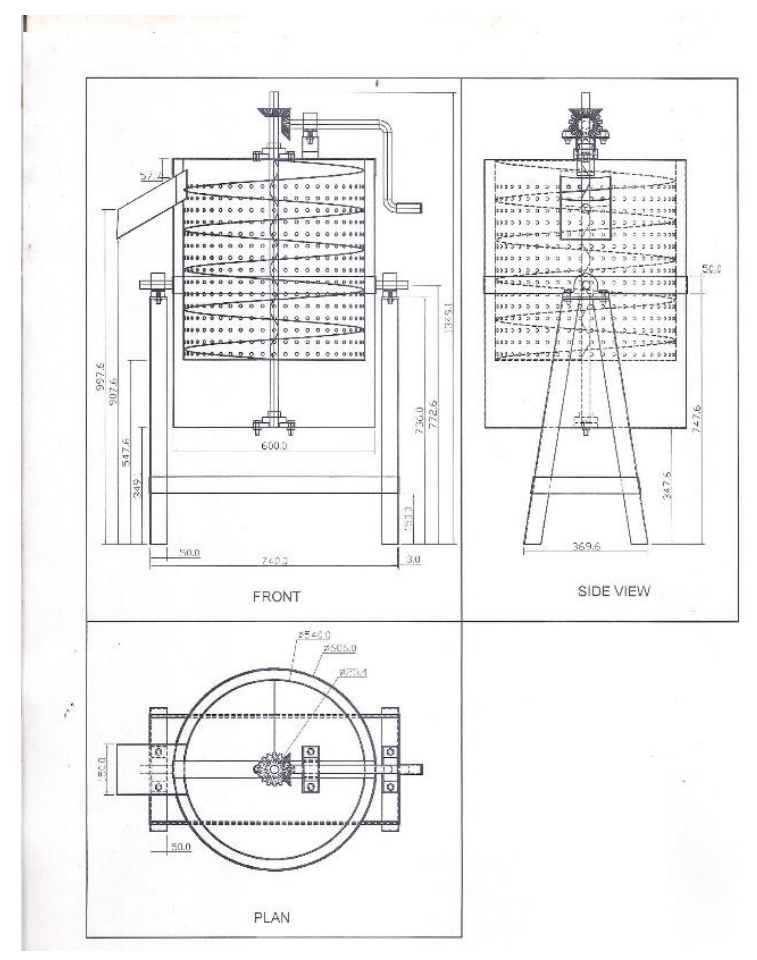

Fig. A: Orthographic Projection of the developed Millet Destoner 